\title{
The Psychiatric Presentation of Fragile X: Evolution of the Diagnosis and Treatment of the Psychiatric Comorbidities of Fragile X Syndrome
}

\author{
Michael R. Tranfaglia \\ FRAXA Research Foundation, Newburyport, Mass., USA
}

\section{Key Words \\ Psychopharmacology • Pathophysiology • Behavior • Phenotype $\cdot$ Autism spectrum disorders $\cdot$ Disease mechanisms}

\begin{abstract}
Fragile $\mathrm{X}$ syndrome (FXS) is the leading inherited cause of mental retardation and autism spectrum disorders worldwide. It presents with a distinct behavioral phenotype which overlaps significantly with that of autism. Unlike autism and most common psychiatric disorders, the neurobiology of fragile $X$ is relatively well understood. Lack of the fragile $X$ mental retardation protein causes dysregulation of synaptically driven protein synthesis, which in turn causes global disruption of synaptic plasticity. Thus, FXS can be considered a disorder of synaptic plasticity, and a developmental disorder in the purest sense: mutation of the FMR1 (fragile $X$ mental retardation 1) gene results in abnormal synaptic development in response to experience. Accumulation of this abnormal synaptic development, over time, leads to a characteristic and surprisingly consistent behavioral phenotype of attention deficit, hyperactivity, impulsivity, multiple anxiety symptoms, repetitive/perseverative/stereotypic behaviors, unstable affect, aggression, and self-injurious behavior. Many features of the behavioral and psychiatric phenotype
\end{abstract}

of FXS follow a developmental course, waxing and waning over the life span. In most cases, symptoms present as a mixed clinical picture, not fitting established diagnostic categories. There have been many clinical trials in fragile $\mathrm{X}$ subjects, but no placebo-controlled trials of adequate size or methodology utilizing the most commonly prescribed psychiatric medications. However, large and well-designed trials of investigational agents which target the underlying pathology of FXS have recently been completed or are under way. While the literature offers little guidance to the clinician treating patients with FXS today, potentially disease-modifying treatments may be available in the near future.

Copyright $\odot 2011$ S. Karger AG, Basel

\section{Introduction}

Psychiatric disorders are common in the general population. The clinical presentations of the major psychiatric disorders, such as schizophrenia, bipolar disorder, major depression, and the various anxiety disorders, are all highly variable, but well described, systematically characterized, and extensively subtyped. These disorders cause massive morbidity and mortality in all human societies and require enormous healthcare expenditures each year. However, despite generous research funding

\section{KARGER \\ Fax +4161306 1234 \\ E-Mail karger@karger.ch}

www.karger.com (c) 2011 S. Karger AG, Basel

0378-5866/11/0335-0337\$38.00/0

Accessible online at: www.karger.com/dne
Michael Tranfaglia, MD

FRAXA Research Foundation

45 Pleasant St.

Newburyport, MA 01950 (USA)

Tel. +1 978462 1990, E-Mail mtranfaglia@fraxa.org 
and decades of investigation, very little is known about any of these conditions at the synaptic, molecular, or genetic level.

In stark contrast, fragile X syndrome (FXS) is a rare genetic disease which is associated with a characteristic psychiatric phenotype. While the clinical features of FXS have not been studied in the same detailed and systematic fashion as the major psychiatric disorders, recent research has yielded a remarkably detailed understanding of the pathophysiology of fragile X. The discovery of the FMR1 (fragile X mental retardation 1) gene in the early 1990s, the characterization of its normal protein product, FMRP (fragile X mental retardation protein) and the development of mouse gene knockout technology have allowed for precise delineation of basic mechanisms of disease at the molecular and synaptic levels, with the prospect of specific treatment in the very near future.

FXS is the most common monogenic cause of mental retardation and autism spectrum disorders worldwide. As such, it has attracted much attention as a model for the study of autism and other developmental disorders. Although individuals with FXS present with significant behavioral and emotional problems, studies of the psychiatric comorbidities seen in males with FXS have been less common than studies of the genetics of the condition, or of the basic neurobiology of fragile $\mathrm{X}$ animal models. This has led to a curious paradox, an inversion of the usual situation in psychiatry: our understanding of the biology of FXS is advancing much more rapidly than our grasp of the clinical phenomenology of this disorder.

Clinically, FXS presents a complex but rather consistent behavioral phenotype. The physical features of FXS were described in the 1940s, long before the genetic basis of the mutation was understood, as these features were recognized in association with X-linked mental retardation. Understanding of the psychiatric phenotype has come only more recently. This paper will focus on the intriguing clinical presentation of males with a full mutation of the FMR1 gene, and how our rapidly growing understanding of the biology of fragile X may inform our view of the pathophysiology of psychiatric disease in general.

\section{Early History of Behavioral Phenotyping of FXS}

It is worth noting at the outset that all of the studies published before 1992 (and some shortly thereafter) used cytogenetic testing to establish the diagnosis of FXS. This older diagnostic technique is less sensitive than current
DNA-based methods which can directly assess mutations of the FMR1 gene. Thus, it can be assumed that many cases of mosaic FXS were missed, and that earlier reports of FXS behavioral phenotypes are based on cases with relatively low levels of mosaicism (and thus, more severely affected individuals). More advanced diagnostics have led to an appreciation of a wider degree of involvement: a 'fragile X spectrum' with classically affected, full mutation males at one end (severe involvement) and virtually unaffected females at the other end. In between, various levels of mosaicism in mutation size (with all females essentially mosaic due to a second, unaffected copy of the gene) and methylation status of the mutated FMR1 gene appear to account for much of the variability in clinical presentation. Ultimately, lack of FMRP, the normal protein product, is thought to cause FXS. While the prevailing opinion in the field is that lower FMRP levels result in more severe phenotypes, this is difficult to demonstrate in vivo. Mosaicism appears to affect various tissues differentially [Dobkin et al., 1996], and correlations between IQ and FMRP levels in blood are imperfect [Hall et al., 2008].

Aside from the general recognition of intellectual impairment and the physical phenotype, including a long face and large ears, the earliest reports of specific CNS effects of the fragile X mutation emphasized the autisticlike presentation of many males with FXS [Brown et al., 1982a, 1982b]. Indeed, some early reports found very high rates of undiagnosed FXS in autism populations [Blomquist et al., 1985; Brown et al., 1986; Fisch et al., 1986; Wahlström et al., 1986]. As fragile X diagnostics have become more sophisticated, and testing for the condition more commonplace, these reported rates of undiagnosed fragile $\mathrm{X}$ among autism populations have, not surprisingly, declined. However, FXS continues to be associated with high rates of stringently defined autism (i.e. autistic disorder) and autism spectrum disorders (i.e. pervasive developmental disorder). Nearly one third of young males with fragile X score in the autistic range on the Childhood Autism Rating Scale, with more than two thirds scoring above the normal cutoff [Bailey et al., 2001]. A more recent study using the Autism Diagnostic Observation Schedule found that $35.1 \%$ of young males scored in the autistic range [Hall et al., 2010].

One of the earliest attempts to describe the FXS phenotype comprehensively, including the behavioral phenotype, examined 21 males with fragile $\mathrm{X}$ from 2 to 21 years of age. The authors noted that while the well-known physical phenotype often did not manifest until later in 
life, 'the psychological profile of these boys, on the other hand, was remarkably uniform' [Fryns et al., 1984]. They observed that intellectual impairment ranged from mild to severe, but with a mean IQ of 43.67 and with most subjects $(16 / 21)$ in the moderately retarded range. All were described as having significant fine and gross motor coordination problems, and all were significantly delayed in their language development. Twenty of 21 subjects (95.2\%) showed 'hyperkinetism' and 19 (90.5\%) were described as having 'concentration difficulties'. The authors note:

In all boys a hyperkinetic syndrome was present, in some patients leading to chaotic behaviour, more pronounced in the youngest age group. The degree of overactivity and agitation was not directly related with the IQ, and was even more evident in the better IQ group. The majority of the affected males were moderately mentally retarded (16 out of 21 ), but one boy was slightly mentally retarded, and 4 others were deeply retarded with IQ's of less than 25 . The disturbing agitation was associated with high emotional lability and resulted in automutilation with characteristic hand biting in about two-thirds of these boys. On the other hand it is remarkable to note that in at least three patients the diagnosis of infantile autism was proposed before the fragile $\mathrm{X}$ screening was performed.

Fryns [1984] went on to study a larger population of fragile X males in which he confirmed the previously described behavioral phenotype of hyperactivity and impaired attention, marked anxiety with poor eye contact, affective lability, aggression, self-injurious behavior, and autistic features such as repetitive/perseverative/stereotypic behaviors. This basic formulation of the fragile $\mathrm{X}$ behavioral phenotype has remained intact to the present day, with substantial confirmation of these basic findings in subsequent studies [Largo and Schinzel, 1985; Gillberg et al., 1986; Veenema et al. 1987; Bregman et al., 1988]. Also confirmed was the observation that the marked hyperactivity seen in young males with fragile $\mathrm{X}$ appeared to follow a distinct developmental course: boys with FXS actually appeared hypoactive early in life, but became markedly hyperactive in the preschool years. This 'hyperkinesis' and impulsiveness then clearly decreased with age, even as IQ was observed to decline [Borghgraef et al., 1987]. Many of the disruptive behaviors seen in fragile X also appear to decline over time when examined longitudinally, while shy behavior and poor eye contact remain relatively constant, and significantly different from control subjects with developmental disorders [Einfeld et al., 1999].

Thus, the classical behavioral phenotype of FXS is described as 'poor eye contact, excessive shyness, anxiety, hand flapping, hand biting, aggression, tactile defensive-

The Psychiatric Presentation of Fragile X ness, attention deficits, hyperactivity, impulsivity, hyperarousal to sensory stimuli, and ASD (Autism Spectrum Disorder)' [Hagerman et al., 2009].

\section{Systematic Behavioral Phenotyping}

While initial efforts to delineate the behavioral phenotype of FXS were often naturalistic and descriptive, with small numbers of patients, subsequent studies generally utilized more rigorous methods of quantifying behavior. Critics of the notion of a behavioral or psychiatric phenotype of fragile $\mathrm{X}$ have argued that any attempt to describe a behavioral phenotype must control for developmental age, with the accepted idea that many of the behavioral 'problems' associated with FXS could be seen as normal behavior in an individual with lower mental age [Fisch, 1993; Einfeld and Hall, 1994]. With further development in the FXS field, studies employing controls matched for IQ or mental age became standard, and the original description of the behavioral phenotype was essentially confirmed [Reiss and Freund, 1992; Wiegers et al., 1993]. However, it is important to recognize that there is also some circular logic in this line of thinking. It may not be possible to match subjects precisely based on IQ or mental age, since few standardized psychometric instruments are validated in all the various developmental disorders across the age spectrum. Cognitive assessment of subjects with FXS is notoriously difficult, and may be unreliable [Einfeld et al., 1994], though ongoing efforts aim to improve reliability of cognitive testing [Hessl et al., 2009]. Specific behavioral disturbances in subjects [attention deficit-hyperactivity disorder (ADHD) in FXS, for instance] may affect testing performance (and thus IQ or mental age), even though this behavior itself is not a formal component of intelligence. Thus, the behavioral phenotype itself may confound attempts to rigorously characterize the behavioral phenotype of FXS.

Subsequent studies have shown that fragile $\mathrm{X}$ males differ from IQ-matched controls with non-fragile X developmental disorders in that they have more abnormal language, tactile defensiveness, poor self-control, poor eye contact/shyness, and hand flapping [Lachiewicz et al., 1994; Einfeld et al., 1994]. Using similar methodology of parent/caregiver and teacher ratings on the Aberrant Behavior Checklist [Aman et al., 1985], fragile X males showed significantly higher levels of hyperactivity, stereotypic movements, and unusual speech compared to matched control subjects [Baumgardner et al., 1995]. Again, counter to the notion that developmental delay per 
se might explain many observed FXS symptoms, a distinct behavioral phenotype was seen in FXS subjects compared to groups with fetal alcohol syndrome, tuberous sclerosis, and Prader-Willi syndrome, with the latter two groups showing no distinct pattern of behavioral disorder [Steinhausen et al., 2002]. As a group, FXS subjects were more anxious than the other disease groups, more autistic, but also paradoxically more empathetic. This finding lies at the heart of a controversy still unsettled; subjects with FXS appear quite connected to others, but painfully anxious. Scores on autism rating scales are high, yet they clearly seek social interaction, suggesting a qualitative difference between FXS and autism which is not easily captured on many rating instruments [Hall et al., 2010].

In one of the few studies employing a structured psychiatric interview, male children and teens with FXS were found to have high rates of ADHD (74\%) and oppositional defiant disorder (29\%), as well as functional enuresis and encopresis [Backes et al., 2000]. Diagnoses of separation anxiety disorder and obsessive-compulsive disorder were seen in a smaller number of subjects (10 and 2\%, respectively). This work highlights the difference between a clinical presentation with multiple psychiatric symptoms and a clinical presentation which meets criteria for a formal psychiatric diagnosis. As is the case in autism and other developmental disorders, studies in subjects with fragile $\mathrm{X}$ have typically found high levels of behavioral and psychiatric symptoms, but relatively few formally diagnosable psychiatric diagnoses according to current (DSM-III/IV) nomenclature.

In one study of 63 children with full mutation FXS and 56 children without disabilities matched by mental age, ADHD symptoms were seen in 59\% of FXS subjects, based on parent and teacher ratings (not formal examination) [Sullivan et al., 2006]. The figures produced by this type of cross-sectional study of younger children can be seen as a point prevalence figure, compared to longitudinal studies showing lifetime prevalence, which would presumably be higher. Another study in 31 boys and 29 girls with FXS aged 5-20 years showed that compulsive behavior occurred in $72 \%$ of boys and self-injurious behavior (primarily hand biting) occurred in $58 \%$, but the behaviors were not necessarily associated in individuals [Hall et al., 2008].

As is the case with ADHD in FXS, many of the other psychiatric manifestations of FXS appear to follow a developmental course; in other words, they are noted to change over the life span. Perhaps this should not be surprising: even a phenotype as objectively biological in ori- gin as epilepsy has been documented to follow a developmental course, both in fragile X knockout mice [Yan et al., 2004] and in humans with FXS [Musumeci et al., 1999; Sabaratnam et al., 2001]. As noted above, the disruptive behaviors seen in FXS generally decline over time, but aggression has often been observed to worsen dramatically during early adolescence, before dissipating in young adulthood. This appears to correspond roughly to puberty and the hormonal transition to sexual maturity [Tsiouris and Brown, 2004]. Although males with fragile X typically live a normal life span, no systematic studies of older males with fragile $\mathrm{X}$ have been published. This represents a major gap in our understanding, especially since most clinical trials of investigational new drugs need to be conducted in adults for practical, ethical, and regulatory reasons.

The psychiatric presentation of FXS can be seen as a group of symptom clusters with similarities to established psychiatric disorders as commonly defined in the general population. Most of the commonly observed behavioral and psychiatric symptoms of FXS would then fall into the following categories: attention deficit and hyperactivity/impulsivity, anxiety disorders, and affective disorders. Aggression and self-injurious behavior, especially the hand biting typically described in FXS, could be considered a separate symptom domain. In the absence of compelling evidence, they are treated here as outward manifestations of anxiety, mood lability, and poor impulse control.

\section{Attention Deficit and Hyperactivity}

As noted above, ADHD is the most common diagnosable condition in FXS patients, with most males meeting formal criteria at some point in their lives. However, this condition is typically not stable over time in any given individual. While the same might be said for ADHD in the general population, the progression of symptoms in individuals over relatively brief periods of time can be especially pronounced in FXS. Very young children with fragile $\mathrm{X}$ are often noted to be physically hypoactive, with somewhat impaired attention. Preschool children may display dramatic increases in activity levels, leading to markedly disruptive behavior. As children grow, hyperactivity declines as body mass increases, while problems with attention continue throughout life. In some ways, this is similar to the course of ADHD in the normal population, though the degree of hyperactivity in FXS is impressive. There is also evidence that the attention deficit 
seen in males with fragile $\mathrm{X}$ has a specific profile [Munir et al., 2000] which is distinct from other causes of developmental disorders, suggesting that the attention problems seen in the course of FXS may represent more than just nonspecific immaturity. Animal models of FXS show a corresponding phenotype: Fmrl knockout mice display increased locomotor activity [Pieretti et al., 1991; Yan et al., 2004] and Drosophila dfmrl mutants have a disturbed circadian rhythm, a fly correlate of human hyperactivity [Dockendorff et al., 2002].

Clinical symptoms of ADHD are generally considered to be manifestations of dysfunction in dopamine pathways regulating attention, impulse control, and motivation [Volkow et al., 2010]. Given the nearly universal clinical finding of attention deficit and hyperactivity in boys with FXS, abnormalities in dopamine systems would be expected. Dopaminergic dysfunction in fragile $\mathrm{X}$ has been suggested by a number of studies, including evidence that the eye blink rate is abnormal in boys with fragile X [Roberts et al., 2005], and that attention is significantly impaired in Fmr1 knockout mice [Moon et al., 2006]. More recent studies in the FXS mouse model suggest specific abnormalities in forebrain $D_{1}$ signaling [Wang et al., 2008], including excessive G-protein-coupled receptor kinase 2 function, in agreement with previous evidence that amphetamine can rescue impaired object recognition in Fmrl knockout mice [Ventura et al., 2004]. Additionally, dopamine release may be specifically impaired in Fmrl knockout mice [Fulks et al., 2010].

While an early controlled trial of stimulant medication for ADHD symptoms in fragile $\mathrm{X}$ children showed modest benefit [Hagerman et al., 1988], the study suffered from a number of methodological shortcomings, including a small number of subjects, the use of two different study drugs, and a very brief duration of treatment. Even with a brief exposure to the active drug, significant psychiatric side effects were seen in some subjects. Indeed, increased anxiety, irritability, and mood lability are commonly noted side effects of stimulant medications in FXS patients [Berry-Kravis and Potanos, 2004]. This parallels the experience in the treatment of developmental disorders generally, with stimulant medication often poorly tolerated in more intellectually disabled populations [Posey and McDougle, 2000].

Dysregulation of autonomic nervous system function has also been noted in children and adolescents with fragile X [Hall et al., 2009], and this may contribute to attention deficit and hyperactivity, as well as the classically described sensitivity to sensory input and environmental stress. Another brief study of mixed stimulant medica- tions in a group of fragile $\mathrm{X}$ children with ADHD [Hagerman et al., 2002] compared to IQ-matched, non-fragile X subjects with ADHD showed specific improvement in electrodermal responses in fragile X subjects, suggesting enhancement of inhibitory neurotransmission. Stimulant trials in FXS subjects of longer treatment duration are warranted, especially since psychostimulant medications are often prescribed to patients for years. In addition, chronic use of amphetamines and methylphenidate is well known to induce tolerance, so effects of treatment may vary significantly from the acute responses seen in these trials.

Given the relatively high rate of adverse psychiatric effects seen with the use of stimulant medications in FXS, nonstimulant medications may have a particularly important role in the treatment of ADHD symptoms in fragile X. One of the largest controlled trials to date in FXS subjects found a modest but statistically significant benefit from L-acetyl carnitine in the treatment of ADHD symptoms [Torrioli et al., 2008]. However, this study did not utilize the now widely accepted Aberrant Behavior Checklist or Clinical Global Improvement scales, focusing instead on ADHD measures. The modest effect of treatment may not be clinically meaningful, though statistically significant improvements in socialization and adaptive behavior were also noted with L-acetyl carnitine treatment. The authors had originally proposed that Lacetyl carnitine might partially restore FMRP expression, but this was not found to be the case in the course of these studies. Thus, the mechanism of action of L-acetyl carnitine remains unclear. On a similar note, a much smaller, open trial of valproic acid [Torrioli et al., 2010] also sought to restore FMRP expression via inhibition of histone deacetylase. This study found improvement in ADHD symptoms in FXS subjects, but no expression of FMRP was seen. Other nonstimulant medications, especially the sympatholytic agents clonidine and guanfacine, are frequently utilized to treat hyperactivity and hyperarousal in FXS, as in other developmental disorders [Hagerman et al., 2009]; however, no systematic studies of these agents in FXS subjects have been performed to date.

\section{Anxiety Cluster}

Males with fragile X display a broad range of anxiety symptoms, but these symptoms do not usually fit into the established categories of major anxiety disorders employed by the Diagnostic and Statistical Manual of Mental 
Disorders (panic disorder, specific phobia, social phobia, obsessive-compulsive disorder, generalized anxiety disorder, and post-traumatic stress disorder). Indeed, individual males with fragile $\mathrm{X}$ are commonly observed with simultaneous symptoms of all these anxiety disorders - a decidedly rare occurrence in the developmentally normal population. However, the presence of a known medical condition (the genetic disease of fragile X) can be seen as an exclusionary factor preventing most of these diagnoses.

Within the classically described behavioral phenotype of fragile X, elements such as poor eye contact, gaze aversion, and excessive shyness are obviously primarily anxiety-based, and strongly reminiscent of social phobia. However, the subjective experience of anxiety may contribute significantly to other aspects of the phenotype, such as hand flapping, hand biting, aggression, and autistic symptoms [Boyle and Kaufmann, 2010]. Thus, anxiety appears to contribute significantly to the morbidity of FXS. As previously noted, a minority of males with FXS meet formal criteria for a diagnosis of obsessivecompulsive disorder, while 'compulsive symptoms' have been noted in several studies in a large majority of subjects with FXS. In most cases of FXS, individuals exhibit symptoms strongly reminiscent of obsessions and compulsions, but which do not meet the precise psychiatric definitions for these symptoms. Often, pleasure is derived from repetitive and 'compulsive' behaviors, in contrast to the ego-dystonic nature of true obsessions and compulsions. These are probably more precisely termed repetitive, perseverative, or stereotypic behaviors. Similarly, younger children with FXS will meet criteria for separation anxiety disorder in a small minority of cases [Backes et al., 2000], while symptoms of separation anxiety, social phobia, panic, and agoraphobia are seen clinically at a much higher rate. As is the case for many other formal psychiatric disorders, exclusive occurrence during the course of a pervasive developmental disorder (as is typical in cases of FXS) precludes a formal diagnosis of separation anxiety disorder.

Proper function of inhibitory GABAergic circuits appears to be critical to the regulation of anxiety. Indeed, one frequently cited, unifying explanation for many causes of autism spectrum disorders is the disruption of excitatory/inhibitory circuit balance [Rubenstein and Merzenich, 2003]. Deficits in GABAergic function have been proposed as the basis for a number of fragile $\mathrm{X}$ symptoms, including anxiety and epilepsy, and decreased expression of GABA receptors in the fragile $\mathrm{X}$ mouse model has been demonstrated [D'Hulst et al., 2006].
However, this group's finding of general downregulation of multiple elements of the GABA neurotransmission apparatus suggests that this may be a compensatory change, or perhaps secondary to abnormalities in glutamate systems. Results appear to vary significantly by brain region, but excitatory (glutamatergic) drive onto inhibitory interneurons in the somatosensory cortex of Fmr1 knockout mice is deficient [Gibson et al., 2008], resulting in decreased inhibitory circuit function. This can be rescued by a number of $\mathrm{GABA}_{\mathrm{A}}$ agonists, including novel agents such as gaboxadol [Olmos-Serrano et al., 2010].

There have been no systematic trials of traditional $\mathrm{GABA}_{\mathrm{A}}$ agonists in FXS subjects, perhaps because the clinical experience with these agents has not been encouraging, with generally poor response and high rates of adverse behavioral effects. 'Paradoxical' reactions to sedatives are of concern in developmentally disabled populations [Marrosu et al., 1987], and FXS patients can display behavioral disinhibition, irritability, and even aggression when treated with benzodiazepines. However, some patients have been prescribed these treatments for occasional use, such as dental procedures, with good effect. Variability in inhibitory dysfunction across different brain regions may explain the inconsistent response of humans with FXS to $\mathrm{GABA}_{\mathrm{A}}$ agonists.

Specific abnormalities in $\mathrm{GABA}_{\mathrm{B}}$ function have been demonstrated in the Fmrl knockout mouse model, and these can be rescued with $\mathrm{GABA}_{\mathrm{B}}$ agonists [Zupan and Toth, 2008b; Pacey et al., 2009]. There is also evidence that these abnormalities may have their origins in maternal environment, or other epigenetic factors [Zupan and Toth, 2008a]. Results of a large, multicenter, controlled trial of arbaclofen, a proprietary $\mathrm{GABA}_{\mathrm{B}}$ agonist, in 54 subjects with FXS have been reported as positive (http:// www.seasidetherapeutics.com/about_us/news_mediarelease_2010-07-26.pdf), but not yet reviewed or published. However, the study compound apparently failed to separate from placebo on primary outcome measures in the overall study population, showing a statistically significant effect only in a more socially withdrawn subpopulation.

Serotonergic deficits have long been hypothesized in FXS, in light of the broad spectrum of anxiety disorders seen in FXS patients at all ages. Subjects with FXS who have the high-transcribing, long genotype of the serotonin transporter have higher rates of aggression, selfinjurious behavior, and stereotypy [Hessl et al., 2008]. While there have been no systematic studies of SSRIs or other serotonergic anxiolytic therapies in FXS, SSRIs have been widely used in the clinical treatment of FXS 
[Berry-Kravis and Potanos, 2004], as is the case in autism spectrum disorders generally. However, controlled studies of their effectiveness in autism spectrum disorders have yielded mixed results [Kolevzon et al., 2006; King et al., 2009; Williams et al., 2010], perhaps because of the low doses utilized in some of the studies. Successful trials, especially in adults with autism spectrum disorders, have utilized higher doses typically associated with the treatment of obsessive-compulsive disorder [McDougle et al., 1996]. Parent surveys, while lacking in methodological rigor, indicate a general perception among caregivers of SSRI efficacy in individuals with FXS [Boyle and Kaufmann, 2010]. Adverse effects of SSRIs include significant activation, especially in children, which can aggravate preexisting symptoms of hyperactivity and can be a major dose-limiting side effect. Gastrointestinal disturbance associated with SSRIs can also aggravate encopresis, another common symptom of FXS.

\section{Affective Cluster}

As described by Backes et al. [2000], males with FXS rarely meet formal criteria for a diagnosis of a major mood disorder as defined in DSM-III or DSM-IV. Diagnoses such as major depression or bipolar disorder require periods of abnormal mood that are sustained, whereas individuals with fragile $\mathrm{X}$ will typically exhibit labile mood, irritability, self-injurious behavior, and aggressive outbursts of a more fleeting and episodic nature, not meeting the conventional duration criteria. These episodes are typically provoked by environmental stressors, and are less frequent in familiar or more structured settings. However, affective symptoms can be severe and disruptive, and are a common target for psychopharmacologic intervention. Once again, SSRIs are a commonly employed treatment strategy along with other antidepressants, anticonvulsants, and atypical antipsychotics in more severe cases [Tsiouris and Brown, 2004]. There have been no clinical trials of any size, open or controlled, of antidepressants or anticonvulsants for the treatment of affective symptoms of FXS (the 2010 study of valproic acid by Torrioli et al. focused exclusively on ADHD symptoms, while valproic acid is used in psychiatry primarily as a mood stabilizer).

While formal thought disorders are generally considered rare in FXS, as in autism spectrum disorders [Solomon et al., 2008], antipsychotic medications are commonly used to treat affective lability, agitation, and ag- gression [McDougle et al., 2008]. Indeed, risperidone was the first treatment specifically approved by the FDA for treatment of autism symptoms (specifically, irritability). A small pilot study of open-label aripiprazole showed promising results in the treatment of irritability in fragile X [Erickson et al., 2010]. No controlled studies of antipsychotics, either typical or atypical, have been conducted in FXS subjects, despite high rates of drug utilization.

Dysregulation of cortisol secretion in children with FXS has been shown via salivary sampling [Hessl et al., 2002; Hall et al., 2006], and this has been proposed as a potential mechanism for exaggerated stress responsiveness and affective symptoms in FXS. Rather than showing exaggerated cortisol response to stress, as originally hypothesized, subjects with FXS had high baseline levels of cortisol secretion, which correlated with behavioral disturbances. A small pilot study in FXS subjects of the antiglucocorticoid agent mifepristone [Reiss, unpublished data] showed no therapeutic benefit, and possible serious adverse effects. Studies in the Fmrl knockout mouse have yielded conflicting results, with an initial study showing subtle differences in corticosterone (the mouse equivalent of human cortisol) secretion following exposure to stress [Markham et al., 2006], but a subsequent study showing no statistically significant abnormalities at baseline or in response to stress [Qin and Smith, 2008].

Abnormal activation of the ubiquitous kinase GSK3 $\beta$ has been demonstrated in the FXS mouse model, and rescue of prominent phenotypes has been accomplished with GSK3 $\beta$ inhibitors and lithium, also a known inhibitor of GSK3 $\beta$ [Mines et al., 2010; Liu et al., 2010; Choi et al., 2010]. Since GSK3 $\beta$ inhibition is thought to be the primary mechanism of action of lithium in the treatment of bipolar disorder, numerous GSK3 $\beta$ inhibitors are under investigation as lithium alternatives, though none are currently available for use in psychiatry. Activity of brain GSK $3 \beta$ may therefore be seen as an important regulator of mood states, and this abnormality may represent an important area of overlap between FXS and bipolar disorder [Li and Jope, 2010]. Based partly on this work, an open trial of lithium was conducted in 15 FXS subjects aged between 6 and 23 years; subjects showed significant improvement in total Aberrant Behavior Checklist scores, as well as RBANS List Learning [Berry-Kravis et al., 2008]. Lithium treatment also resulted in normalization of ERK phosphorylation rates, a putative biomarker of fragile X. These results await replication in a larger, controlled trial. 


\section{Disease-Specific Treatment Strategies}

The availability of animal models of FXS, particularly Fmrl knockout mice and dfmr null fruit flies, has allowed for the development of therapeutics which specifically target the basic disease mechanisms in fragile X.

Initial attempts at specific treatment (rather than general, symptom-based approaches) for fragile $\mathrm{X}$ focused on the hypothesis that fragile $\mathrm{X}$ may be associated with a defect in folate metabolism. This idea was based on the original discovery of the 'fragile' site on the X chromosome after cells were incubated in a folate-deficient medium. However, no actual abnormalities of folate metabolism have ever been demonstrated in humans with fragile X or in animal models. While this hypothesis generated great enthusiasm and much off-label prescription, initial trials were of poor methodology and led to spurious reports of benefit from treatment with high-dose folic acid. Some initial reports even claimed rescue of the chromosomal fragile site in patients [Harpey, 1982], while later controlled studies showed no improvement with folic acid treatment [Fisch et al., 1988]. A subsequent controlled trial of folinic acid, a more potent derivative of folic acid, also showed no benefit [Strom et al., 1992].

The folic acid experience in FXS may have served as a cautionary tale, as most clinicians have pursued more evidence-based approaches in the intervening years.

The seminal finding that FMRP is translated in response to synaptic activity [Weiler et al., 1997], mediated by metabotropic glutamate receptors, shifted research efforts to understanding the role of glutamatergic neurotransmission. Since glutamate is the major excitatory neurotransmitter in the brain, abnormalities in this system could explain the global effects of the fragile X mutation across multiple brain regions and multiple neurotransmitter systems.

In an early attempt to modulate glutamate in FXS patients by enhancement of AMPA receptor activity, the 'ampakine' compound CX516 was used in a phase II controlled clinical trial in 49 adults with FSX [Berry-Kravis et al., 2006]. No statistically significant therapeutic effects were seen, though the low rate of adverse effects suggests underdosing. Subsequent evidence also indicates that the potency of CX516 is far less than originally thought. While more potent and longer acting ampakines are being developed, these agents will require many years of further development before they can be considered for marketing. However, ongoing investigation has confirmed that AMPA receptor surface expression is reduced in fragile $\mathrm{X}$ animal models, so enhancement of
AMPA receptor function remains a viable therapeutic target in FXS [Nakamoto et al., 2007].

Recent findings have suggested that glutamatergic dysfunction most likely underlies the bulk of the CNS phenotype in FXS [Bear, 2005], and the 'mGluR theory of fragile X' [Bear et al., 2004] has received widespread acceptance. Extensive preclinical validation in animal models of FXS [Yan et al., 2005; Dölen et al., 2010] has led to clinical trials of potentially disease-modifying agents which antagonize metabotropic glutamate receptors. Indeed, several classes of therapeutics have the potential to target these abnormalities with relative specificity, including mGluR1, mGluR2/3, and mGluR5 antagonists [Choi et al., 2010].

The investigational agent fenobam, an mGluR5 antagonist previously developed as an anxiolytic, but never marketed, showed excellent tolerability in adult FXS subjects, with some suggestions of efficacy in a small phase I/II trial [Berry-Kravis et al., 2009]. A recently completed, but as yet unpublished, phase II trial in FXS adults of the more modern mGluR5 antagonist AFQ056 has been reported as successful, and phase III trials are proceeding; phase II trials of the mGluR5 antagonist RO4917523 are nearing completion, and phase II trials of a third mGluR5 antagonist, STX107, in FXS subjects are about to begin (see http://clinicaltrials.gov/ct2/results?term=fragile+X).

A number of available agents possess glutamatergic effects, and pilot studies have examined their potential utility in treating FXS subjects. There have been reports of modest efficacy in small, open-label pilot studies in FXS subjects with memantine [Erickson et al., 2009] and acamprosate [Erickson et al., 2010], two agents with weak NMDA receptor antagonism (acamprosate is also thought to act through several other mechanisms, including weak $\mathrm{GABA}_{\mathrm{A}}$ agonism and possible mGluR5 antagonism [Kiefer and Mann, 2010]. The available antibiotic minocycline is thought to modulate glutamate transmission, among many putative therapeutic effects. Minocycline also inhibits matrix metalloproteinase 9, which is excessively activated via mGluR5 in fragile $\mathrm{X}$ animal models [Bilousova et al., 2009]. An open trial of minocycline in 20 adolescents and young adults with FXS showed large and statistically significant reductions in Aberrant Behavior Checklist scores over the course of 8 weeks of treatment [Paribello et al., 2010]. A larger, placebo-controlled trial of minocycline in FXS subjects is currently under way. Intriguingly, minocycline has also been shown to be effective in treating the cognitive and negative symptoms of schizophrenia, in a long-term, placebocontrolled trial [Levkovitz et al., 2010]. 


\section{Conclusion}

Males with FXS appear to present with a relatively consistent psychiatric phenotype which overlaps significantly, though not completely, with that of autism. This phenotypic overlap offers the potential to develop novel therapeutic strategies for autism spectrum disorders in the relatively homogeneous fragile $\mathrm{X}$ population. Adding to the appeal of fragile $\mathrm{X}$ as a model for autism is the availability of excellent animal models, with well-established mechanisms of disease. The field of fragile $\mathrm{X}$ research has progressed in the past 20 years from molecular genetics, through cognitive neuroscience, to its current status in clinical trials. As the pace of clinical trials accelerates, more experience is developing in quantifying the behavioral and psychiatric features of FXS, yet this area still lags.

The importance of a proper diagnosis in any medical condition cannot be overemphasized: the best treatments can fail if the diagnosis is incorrect. Psychiatry is unusual among the medical specialties, however, in that excellent treatments exist for a wide variety of disorders, while diagnostic techniques are still relatively primitive. Clinical assessment, by interview and examination, is still the gold standard for the diagnosis of essentially all psychiatric disorders - there are no routine laboratory tests or imaging studies to assist in the diagnosis, other than to rule out possible medical etiologies. The major advance in psychiatric diagnosis in recent decades has been the standardization of diagnostic criteria and terminology for widely recognized disorders. It should not be surprising that FXS has escaped the attention of the editors of DSM-IV. There are only a handful of psychiatrists worldwide involved in fragile $\mathrm{X}$ research, and FXS is a rare disease, especially compared to nearly any psychiatric condition. Thus, we are left with a terminology which is inadequate to describe the behavioral and emotional manifestations of FXS.

While psychiatric comorbidity is extensive in FXS, symptoms do not appear to fit well into established diagnostic categories. Relatively few studies have attempted to estimate rates of psychiatric diagnoses in fragile $\mathrm{X}$ populations; even efforts at describing patterns of psychiatric drug utilization in FXS patients have relied entirely on anecdotal reports or surveys, methods which are highly subject to a number of biases. As a potential solution to this gap in our knowledge, analysis of national healthcare databases is possible in a number of countries. This type of study is clearly warranted, and could inform our understanding of the rates of psychiatric diagnoses and treatments in FXS patients young and old, male and female.

FXS presents with a number of disruptive behaviors, often requiring psychiatric treatment. Many powerful and well-established psychopharmacological treatments exist, but the key question is, how to employ them. Since there have been no methodologically sound clinical trials, of adequate size, in FXS subjects, of any of the commonly used CNS agents, current therapy is guided primarily by clinical experience and by extension of general principles from trials in other populations. Current therapies are employed in a symptom-based manner, since patients with FXS often do not meet formal criteria for a particular psychiatric diagnosis. However, this strategy faces severe limitations. Available agents often improve one symptom cluster (such as ADHD), while aggravating another (such as anxiety), much as anticonvulsants may treat seizures while simultaneously causing cognitive impairment.

Absence of dFMRP leads to dysregulation of monoamine synthesis in Drosophila [Zhang et al., 2005]. Further evidence that FMRP may be involved in the regulation of major neurotransmitter systems, and that its absence can directly lead to psychiatric symptoms is supplied by a preliminary report of low levels of FMRP among non-fragile $\mathrm{X}$ patients with major psychopathology [Fatemi et al., 2010]. Larger studies examining FMRP levels in non-fragile $\mathrm{X}$ populations with autism and other major psychiatric disorders are warranted, as FMRP may be a key regulator not only of learning and memory, but also of mood and anxiety.

Given the limited resources and the relatively small number of subjects available for clinical research, adequate studies of the conventional psychiatric medications most commonly used to treat FXS may not be done in the foreseeable future. Nonetheless, the rapid advances in development of novel disease-specific, and potentially disease-modifying, treatments for fragile $\mathrm{X}$ represent an important opportunity to enhance our understanding of the basic disease mechanisms in a wide range of psychiatric and developmental disorders. 


\section{References}

-Aman MG, Singh NN, Stewart AW, Field CJ (1985): The aberrant behavior checklist: a behavior rating scale for the assessment of treatment effects. Am J Ment Defic 89:485491.

-Backes M, Genç B, Schreck J, Doerfler W, Lehmkuhl G, von Gontard A (2000): Cognitive and behavioral profile of fragile $\mathrm{X}$ boys: correlations to molecular data. Am J Med Genet 95:150-156.

Bailey DB Jr, Hatton DD, Skinner M, Mesibov G (2001): Autistic behavior, FMR1 protein, and developmental trajectories in young males with fragile X syndrome. J Autism Dev Disord 31:165-174.

-Baumgardner TL, Reiss AL, Freund LS, Abrams MT (1995): Specification of the neurobehavioral phenotype in males with fragile X syndrome. Pediatrics 95:744-752.

- Bear MF, Huber KM, Warren ST (2004): The mGluR theory of fragile $\mathrm{X}$ mental retardation. Trends Neurosci 27:370-377.

Bear MF (2005): Therapeutic implications of the mGluR theory of fragile X mental retardation. Genes Brain Behav 4:393-398.

-Berry-Kravis E, Hessl D, Coffey S, Hervey C, Schneider A, Yuhas J, Hutchison J, Snape M, Tranfaglia M, Nguyen DV, Hagerman R (2009): A pilot open label, single dose trial of fenobam in adults with fragile $\mathrm{X}$ syndrome. J Med Genet 46:266-271.

-Berry-Kravis E, Krause SE, Block SS, Guter S, Wuu J, Leurgans S, Decle P, Potanos K, Cook E, Salt J, Maino D, Weinberg D, Lara R, Jardini T, Cogswell J, Johnson SA, Hagerman R (2006): Effect of CX516, an AMPA-modulating compound, on cognition and behavior in fragile X syndrome: a controlled trial. J Child Adolesc Psychopharmacol 16:525-540.

-Berry-Kravis E, Potanos K (2004): Psychopharmacology in fragile $\mathrm{X}$ syndrome - present and future. Ment Retard Dev Disabil Res Rev 10:42-48.

Berry-Kravis E, Sumis A, Hervey C, Nelson M, Porges SW, Weng N, Weiler IJ, Greenough WT (2008): Open-label treatment trial of lithium to target the underlying defect in fragile X syndrome. J Dev Behav Pediatr 29: 293-302.

-Bilousova TV, Dansie L, Ngo M, Aye J, Charles JR, Ethell DW, Ethell IM (2009): Minocycline promotes dendritic spine maturation and improves behavioural performance in the fragile X mouse model. J Med Genet 46: 94-102.

Blomquist HK, Bohman M, Edvinsson SO, Gillberg C, Gustavson KH, Holmgren G, Wahlström J (1985): Frequency of the fragile $X$ syndrome in infantile autism. A Swedish multicenter study. Clin Genet 27:113-117.

Borghgraef M, Fryns JP, Dielkens A, Pyck K, Van den Berghe H (1987): Fragile (X) syndrome: a study of the psychological profile in 23 prepubertal patients. Clin Genet 32:179-186.
Boyle L, Kaufmann WE (2010): The behavioral phenotype of FMR1 mutations. Am J Med Genet Part C Semin Med Genet 154C:469476.

Bregman JD, Leckman JF, Ort SI (1988): Fragile $\mathrm{X}$ syndrome: genetic predisposition to psychopathology. J Autism Dev Disord 18:343354.

Brown WT, Friedman E, Jenkins EC, Brooks J, Wisniewski K, Raguthu S, French JH (1982): Association of fragile $\mathrm{X}$ syndrome with autism. Lancet $\mathrm{i}: 100$.

Brown WT, Jenkins EC, Cohen IL, Fisch GS, Wolf-Schein EG, Gross A, Waterhouse L, Fein D, Mason-Brothers A, Ritvo E, et al (1986): Fragile X and autism: a multicenter survey. Am J Med Genet 23:341-352.

Brown WT, Jenkins EC, Friedman E, Brooks J, Wisniewski K, Raguthu S, French J (1982): Autism is associated with the fragile-X syndrome. J Autism Dev Disord 12:303-308.

$\checkmark$ Choi CH, Schoenfeld BP, Bell AJ, Hinchey P, Kollaros M, Gertner MJ, Woo NH, Tranfaglia MR, Bear MF, Zukin RS, McDonald TV, Jongens TA, McBride SM (2011): Pharmacological reversal of synaptic plasticity deficits in the mouse model of fragile $\mathrm{X}$ syndrome by group II mGluR antagonist or lithium treatment. Brain Res 1380:106-119.

D'Hulst C, De Geest N, Reeve SP, Van Dam D, De Deyn PP, Hassan BA, Kooy RF (2006) Decreased expression of the $\mathrm{GABA}_{\mathrm{A}}$ receptor in fragile X syndrome. Brain Res 1121: 238-245.

Dobkin CS, Nolin SL, Cohen I, Sudhalter V, Bialer MG, Ding XH, Jenkins EC, Zhong N, Brown WT (1996): Tissue differences in fragile X mosaics: mosaicism in blood cells may differ greatly from skin. Am J Med Genet 64:296-301.

Dockendorff TC, Su HS, McBride SM, Yang Z, Choi CH, Siwicki KK, Sehgal A, Jongens TA (2002): Drosophila lacking dfmrl activity show defects in circadian output and fail to maintain courtship interest. Neuron 34: 973-984.

Dölen G, Carpenter RL, Ocain TD, Bear MF (2010): Mechanism-based approaches to treating fragile X. Pharmacol Ther 127:7893.

Einfeld SL, Hall W (1994): When is a behavioural phenotype not a phenotype? Dev Med Child Neurol 36:467-470.

Einfeld SL, Tonge BJ, Florio T (1994): Behavioural and emotional disturbance in fragile X syndrome. Am J Med Genet 51:386-391.

Einfeld S, Tonge B, Turner G (1999): Longitudinal course of behavioral and emotional problems in fragile X syndrome. Am J Med Genet 87:436-439.

Erickson CA, Mullett JE, McDougle CJ (2009): Open-label memantine in fragile $\mathrm{X}$ syndrome. J Autism Dev Disord, E-pub ahead of print.
Erickson CA, Mullett JE, McDougle CJ (2010) Brief report: acamprosate in fragile X syndrome. J Autism Dev Disord 40:1412-1416.

Erickson CA, Stigler KA, Posey DJ, McDougle CJ (2010): Aripiprazole in autism spectrum disorders and fragile X syndrome. Neurotherapeutics 7:258-263.

Fatemi SH, Kneeland RE, Liesch SB, Folsom TD (2010): Fragile X mental retardation protein levels are decreased in major psychiatric disorders. Schizophr Res 124:246-247.

Fisch GS, Cohen IL, Gross AC, Jenkins V, Jenkins EC, Brown WT (1988): Folic acid treatment of fragile X males: a further study. Am J Med Genet 30:393-399.

Fisch GS, Cohen IL, Wolf EG, Brown WT, Jenkins EC, Gross A (1986): Autism and the fragile X syndrome. Am J Psychiatry 143:7173.

Fisch GS (1993): What is associated with the fragile X syndrome? Am J Med Genet 48: $112-121$.

Fryns JP (1984): The fragile X syndrome. A study of 83 families. Clin Genet 26:497-528.

Fryns JP, Jacobs J, Kleczkowska A, van den Berghe $H$ (1984): The psychological profile of the fragile X syndrome. Clin Genet 25:131134

Fulks JL, O’Bryhim BE, Wenzel SK, Fowler SC, Vorontsova E, Pinkston JW, Ortiz AN, Johnson MA (2010): Dopamine release and uptake impairments and behavioral alterations observed in mice that model fragile X mental retardation syndrome. ACS Chem Neurosci 1:679-690.

Gibson JR, Bartley AF, Hays SA, Huber KM (2008): Imbalance of neocortical excitation and inhibition and altered UP states reflect network hyperexcitability in the mouse model of fragile X syndrome. J Neurophysiol 100:2615-2626.

Gillberg C, Persson E, Wahlström J (1986): The autism-fragile-X syndrome (AFRAX): a population-based study of ten boys. J Ment Defic Res 30:27-39.

Hagerman RJ, Berry-Kravis E, Kaufmann WE, Ono MY, Tartaglia N, Lachiewicz A, Kronk R, Delahunty C, Hessl D, Visootsak J, Picker J, Gane L, Tranfaglia M (2009): Advances in the treatment of fragile $\mathrm{X}$ syndrome. Pediatrics 123:378-390.

Hagerman RJ, Miller LJ, McGrath-Clarke J, Riley K, Goldson E, Harris SW, Simon J, Church K, Bonnell J, Ognibene TC, McIntosh DN (2002): Influence of stimulants on electrodermal studies in fragile X syndrome. Microsc Res Tech 57:168-173.

-Hagerman RJ, Murphy MA, Wittenberger MD (1988): A controlled trial of stimulant medication in children with the fragile $\mathrm{X}$ syndrome. Am J Med Genet 30:377-392.

Hall SS, Burns DD, Lightbody AA, Reiss AL (2008): Longitudinal changes in intellectual development in children with fragile X syndrome. J Abnorm Child Psychol 36:927-939. 
Hall S, DeBernardis M, Reiss A (2006): Social escape behaviors in children with fragile $\mathrm{X}$ syndrome. J Autism Dev Disord 36:935-947.

-Hall SS, Lightbody AA, Hirt M, Rezvani A, Reiss AL (2010): Autism in fragile X syndrome: a category mistake? J Am Acad Child Adolesc Psychiatry 49:921-933.

-Hall SS, Lightbody AA, Huffman LC, Lazzeroni LC, Reiss AL (2009): Physiological correlates of social avoidance behavior in children and adolescents with fragile $\mathrm{x}$ syndrome. J Am Acad Child Adolesc Psychiatry 48:320-329.

Hall SS, Lightbody AA, Reiss AL (2008): Compulsive, self-injurious, and autistic behavior in children and adolescents with fragile $\mathrm{X}$ syndrome Am J Ment Retard 113:44-53.

Harpey JP (1982): Treatment of fragile-X. Pediatrics 69:670.

-Hessl D, Glaser B, Dyer-Friedman J, Blasey C, Hastie T, Gunnar M, Reiss AL (2002): Cortisol and behavior in fragile X syndrome. Psychoneuroendocrinology 27:855-872.

-Hessl D, Nguyen DV, Green C, Chavez A, Tassone F, Hagerman RJ, Senturk D, Schneider A, Lightbody A, Reiss AL, Hall S (2009): A solution to limitations of cognitive testing in children with intellectual disabilities: the case of fragile X syndrome. J Neurodev Disord 1:33-45.

-Hessl D, Tassone F, Cordeiro L, Koldewyn K, McCormick C, Green C, Wegelin J, Yuhas J, Hagerman RJ (2008): Brief report: aggression and stereotypic behavior in males with fragile X syndrome - Moderating secondary genes in a 'single gene' disorder. J Autism Dev Disord 38:184-189.

Kiefer F, Mann K (2010): Acamprosate: how, where, and for whom does it work? Mechanism of action, treatment targets, and individualized therapy. Curr Pharm Des 16: 2098-2102.

- King BH, Hollander E, Sikich L, McCracken JT, Scahill L, Bregman JD, Donnelly CL, Anagnostou E, Dukes K, Sullivan L, Hirtz D, Wagner A, Ritz L, STAART Psychopharmacology Network (2009): Lack of efficacy of citalopram in children with autism spectrum disorders and high levels of repetitive behavior: citalopram ineffective in children with autism. Arch Gen Psychiatry 66:583590.

Kolevzon A, Mathewson KA, Hollander E (2006): Selective serotonin reuptake inhibitors in autism: a review of efficacy and tolerability. J Clin Psychiatry 67:407-414.

-Lachiewicz AM, Spiridigliozzi GA, Gullion CM, Ransford SN, Rao K (1994): Aberrant behaviors of young boys with fragile X syndrome. Am J Ment Retard 98:567-579.

- Largo RH, Schinzel A (1985): Developmental and behavioural disturbances in 13 boys with fragile X syndrome. Eur J Pediatr 143: 269-275.
Levkovitz Y, Mendlovich S, Riwkes S, Braw Y, Levkovitch-Verbin H, Gal G, Fennig S, Treves I, Kron S (2010): A double-blind, randomized study of minocycline for the treatment of negative and cognitive symptoms in early-phase schizophrenia. J Clin Psychiatry 71:138-149.

Li X, Jope RS (2010): Is glycogen synthase kinase- 3 a central modulator in mood regulation? Neuropsychopharmacology 35:21432154.

Liu ZH, Chuang DM, Smith CB (2010): Lithium ameliorates phenotypic deficits in a mouse model of fragile X syndrome. Int J Neuropsychopharmacol 25:1-13.

-Markham JA, Beckel-Mitchener AC, Estrada CM, Greenough WT (2006): Corticosterone response to acute stress in a mouse model of Fragile X syndrome. Psychoneuroendocrinology 31:781-785.

Marrosu F, Marrosu G, Rachel MG, Biggio G (1987): Paradoxical reactions elicited by diazepam in children with classic autism. Funct Neurol 2:355-361.

- McDougle CJ, Naylor ST, Cohen DJ, Volkmar FR, Heninger GR, Price LH (1996): A doubleblind, placebo-controlled study of fluvoxamine in adults with autistic disorder. Arch Gen Psychiatry 53:1001-1008.

McDougle CJ, Stigler KA, Erickson CA, Posey DJ (2008): Atypical antipsychotics in children and adolescents with autistic and other pervasive developmental disorders. J Clin Psychiatry 69(suppl 4):15-20.

Mines MA, Yuskaitis CJ, King MK, Beurel E, Jope RS (2010): GSK3 influences social preference and anxiety-related behaviors during social interaction in a mouse model of fragile $\mathrm{X}$ syndrome and autism. PLoS One 5:e9706.

-Moon J, Beaudin AE, Verosky S, Driscoll LL, Weiskopf M, Levitsky DA, Crnic LS, Strupp BJ (2006): Attentional dysfunction, impulsivity, and resistance to change in a mouse model of fragile X syndrome. Behav Neurosci 120:1367-1379.

Munir F, Cornish KM, Wilding J (2000): A neuropsychological profile of attention deficits in young males with fragile $\mathrm{X}$ syndrome. Neuropsychologia 38:1261-1270.

-Musumeci SA, Hagerman RJ, Ferri R, Bosco P, Dalla Bernardina B, Tassinari CA, De Sarro GB, Elia M (1999): Epilepsy and EEG findings in males with fragile $\mathrm{X}$ syndrome. Epilepsia 40:1092-1099.

- Nakamoto M, Nalavadi V, Epstein MP, Narayanan U, Bassell GJ, Warren ST (2007): Fragile $\mathrm{X}$ mental retardation protein deficiency leads to excessive mGluR5-dependent internalization of AMPA receptors. Proc Natl Acad Sci USA 104:15537-15542.

Olmos-Serrano JL, Paluszkiewicz SM, Martin BS, Kaufmann WE, Corbin JG, Huntsman MM (2010): Defective GABAergic neurotransmission and pharmacological rescue of neuronal hyperexcitability in the amygdala in a mouse model of fragile $\mathrm{X}$ syndrome. J Neurosci 30:9929-9938.
Pacey LK, Heximer SP, Hampson DR (2009): Increased GABA(B) receptor-mediated signaling reduces the susceptibility of fragile $\mathrm{X}$ knockout mice to audiogenic seizures. Mol Pharmacol 76:18-24.

- Paribello C, Tao L, Folino A, Berry-Kravis E, Tranfaglia M, Ethell IM, Ethell DW (2010): Open-label add-on treatment trial of minocycline in fragile X syndrome. BMC Neurol 10:91.

Pieretti M, Zhang F, Fu Y H, Warren ST, Oostra BA, Caskey CT, Nelson DL (1991): Absence of expression of the FMR-1 gene in Fragile X syndrome. Cell 66:817-822.

Posey DJ, McDougle CJ (2000): The pharmacotherapy of target symptoms associated with autistic disorder and other pervasive developmental disorders. Harv Rev Psychiatry 8: 45-63.

Qin M, Smith CB (2008): Unaltered hormonal response to stress in a mouse model of fragile $\mathrm{X}$ syndrome. Psychoneuroendocrinology 33 : 883-889.

Reiss AL, Freund L (1992): Behavioral phenotype of fragile X syndrome: DSM-III-R autistic behavior in male children. Am J Med Genet 43:35-46.

Roberts JE, Symons FJ, Johnson AM, Hatton DD, Boccia ML (2005): Blink rate in boys with fragile $\mathrm{X}$ syndrome: preliminary evidence for altered dopamine function. J Intellect Disabil Res 49:647-656

Rubenstein J, Merzenich M (2003): Model of autism: increased ratio of excitation/inhibition in key neural systems. Genes Brain Behav 2: 255-267.

-Sabaratnam M, Vroegop PG, Gangadharan SK (2001): Epilepsy and EEG findings in 18 males with fragile $\mathrm{X}$ syndrome. Seizure 10: 60-63.

Solomon M, Ozonoff S, Carter C, Caplan R (2008): Formal thought disorder and the autism spectrum: relationship with symptoms, executive control, and anxiety. J Autism Dev Disord 38:1474-1484.

-Steinhausen HC, Von Gontard A, Spohr HL, Hauffa BP, Eiholzer U, Backes M, Willms J, Malin Z (2002): Behavioral phenotypes in four mental retardation syndromes: fetal alcohol syndrome, Prader-Willi syndrome, fragile $\mathrm{X}$ syndrome, and tuberosis sclerosis. Am J Med Genet 111:381-387.

Strom CM, Brusca RM, Pizzi WJ (1992): Doubleblind, placebo-controlled crossover study of folinic acid (Leucovorin) for the treatment of fragile X syndrome. Am J Med Genet 44: 676-682.

- Sullivan K, Hatton D, Hammer J, Sideris J, Hooper S, Ornstein P, Bailey D Jr (2006): ADHD symptoms in children with FXS. Am J Med Genet A 140:2275-2288. 
Torrioli MG, Vernacotola S, Peruzzi L, Tabolacci E, Mila M, Militerni R, Musumeci S, Ramos FJ, Frontera M, Sorge G, Marzullo E, Romeo G, Vallee L, Veneselli E, Cocchi E, Garbarino E, Moscato U, Chiurazzi P, D’Iddio S, Calvani M, Neri G (2008): A double-blind, parallel, multicenter comparison of L-acetylcarnitine with placebo on the attention deficit hyperactivity disorder in fragile X syndrome boys. Am J Med Genet A 146:803-812.

- Torrioli M, Vernacotola S, Setini C, Bevilacqua F, Martinelli D, Snape M, Hutchison JA, Di Raimo FR, Tabolacci E, Neri G (2010): Treatment with valproic acid ameliorates ADHD symptoms in fragile $\mathrm{X}$ syndrome boys. Am J Med Genet A 152A:1420-1427.

-Tsiouris JA, Brown WT (2004): Neuropsychiatric symptoms of fragile $\mathrm{X}$ syndrome: pathophysiology and pharmacotherapy. CNS Drugs 18:687-703.

-Veenema H, Veenema T, Geraedts JP (1987): The fragile $\mathrm{X}$ syndrome in a large family. 2. Psychological investigations. J Med Genet 24: 32-38.

- Ventura R, Pascucci T, Catania MV, Musumeci SA, Puglisi-Allegra S (2004): Object recognition impairment in Fmrl knockout mice is reversed by amphetamine: involvement of dopamine in the medial prefrontal cortex. Behav Pharmacol 15:433-442.
Volkow ND, Wang GJ, Newcorn JH, Kollins SH, Wigal TL, Telang F, Fowler JS, Goldstein RZ, Klein N, Logan J, Wong C, Swanson JM (2010): Motivation deficit in ADHD is associated with dysfunction of the dopamine reward pathway. Mol Psychiatry, E-pub ahead of print.

Wahlström J, Gillberg C, Gustavson KH, Holmgren G (1986): Infantile autism and the fragile X. A Swedish multicenter study. Am J Med Genet 23:403-408.

Wang H, Wu LJ, Kim SS, Lee FJ, Gong B, Toyoda H, Ren M, Shang YZ, Xu H, Liu F, Zhao MG, Zhuo M (2008): FMRP acts as a key messenger for dopamine modulation in the forebrain. Neuron 59:634-647.

-Weiler IJ, Irwin SA, Klintsova AY, Spencer CM, Brazelton AD, Miyashiro K, Comery TA, Patel B, Eberwine J, Greenough WT (1997): Fragile X mental retardation protein is translated near synapses in response to neurotransmitter activation. Proc Natl Acad Sci USA 94:5395-5400.

-Wiegers AM, DeVries LB, Curfs LM, Fryns JP (1993): Identical psychological profile and behaviour pattern in different types of mutation in the FMR-1 region. Clin Genet 43: 326-327.
Williams K, Wheeler DM, Silove N, Hazell P (2010): Selective serotonin reuptake inhibitors (SSRIs) for autism spectrum disorders (ASD). Cochrane Database Syst Rev 8:CD004677.

Yan QJ, Asafo-Adjei PK, Arnold HM, Brown RE, Bauchwitz RP (2004): A phenotypic and molecular characterization of the fmrl-tm1Cgr fragile X mouse. Genes Brain Behav 3:337359.

-Yan QJ, Rammal M, Tranfaglia M, Bauchwitz RP (2005): Suppression of two major fragile X syndrome mouse model phenotypes by the mGluR5 antagonist MPEP. Neuropharmacology 49:1053-1066.

Zhang YQ, Friedman DB, Wang Z, Woodruff E 3rd, Pan L, O'Donnell J, Broadie K (2005): Protein expression profiling of the drosophila fragile X mutant brain reveals up-regulation of monoamine synthesis. Mol Cell Proteomics 4:278-290.

Zupan B, Toth M (2008a): Wild-type male offspring of fmr-1+/- mothers exhibit characteristics of the fragile $\mathrm{X}$ phenotype. Neuropsychopharmacology 33:2667-2675.

Zupan B, Toth M (2008b): Inactivation of the maternal fragile $X$ gene results in sensitization of GABAB receptor function in the offspring. J Pharmacol Exp Ther 327:820-826. 